\title{
Implementation of non-linear controller on photovoltaic maximum power point tracker for energy storage equipment charger
}

\author{
Muhammad Imran Hamid ${ }^{1 *}$, Abdul Rajab ${ }^{1}$, Andi Pawawoi ${ }^{1}$ and Rezy Chaniago ${ }^{1}$ \\ ${ }^{1}$ Electrical Eng. Dept. Andalas University - Padang, West Sumatera, Indonesia
}

\begin{abstract}
The portable energy storage system is an infrastructure for providing electrical energy needed to support the recovery process after a natural disaster. This system is a battery arrangement that can be recharged using locally available primary energy sources such as photovoltaic. The main problem in using photovoltaic as the power source for this equipment is to increase the efficiency of power extraction (energy harvesting) during the recharging process. Traditionally, to obtain maximum extraction conditions, conventional linear maximum power point tracker (MPPT) mechanisms such as PID-based MPPT and the like are used. However, if the PV and the storage system works at various locations with environmental conditions behave unusually, the conventional MPPT cannot work accurately and optimally. In this paper, the Fuzzy method for constructing a nonlinear controllerbased MPPT was studied. The step size of the tracking process in the conventional MPPT P\&O method is modified by involving the fuzzy algorithm. This algorithm then is applied to a DC-DC converter to test the performance criteria such as the response and efficiency of the resulting power extraction. The testing and computer simulations show that the conventional MPPT mechanism can provide prospective results through modification and application of a non-linear controller.
\end{abstract}

\section{Introduction}

In the application of PV as part of an electric power supply system, such as a charger for a portable energy storage system (ESS), Fig.1, the efficiency of energy conversion, is the main focus of various development and research efforts.

Energy storage system refers to the device of converting electrical energy from power systems/sources into a form that can be stored for converting back to electrical energy when needed. In disaster conditions, energy storage role to support the critical infrastructure and services. It is providing electrical power. Energy storage systems of all shapes, types, and sizes reduce the time it takes for first responders to begin recovery efforts. ESS must be recharged. If ESS uses renewable, locally primary sources, such as photovoltaic, it must be able to extract the available energy optimally, in high-efficiency mode, and accurately (because the source in the area is limited). All of these requirements can be achieved by implementing advanced, innovative control on ESS components, processes, and systems.

In a PV-based source system, to get maximum efficiency, a control technique is used so that the operating point of the photovoltaic module or array always works at its maximum power condition. This technique is called maximum power point tracking, and it plays a key role in the functioning and effectiveness of the system [1].

The basic conventional maximum power point tracking (MPPT) technique consists of the incremental conductance (IC) technique, the fractional open voltage, and short circuit technique, and the perturb \& observe $(P \& O)$ technique [2]. These techniques are widely used because of their simplicity, ease of implementation, and cost-effectiveness. However, these techniques have their respective drawbacks. The IC and $\mathrm{P} \& \mathrm{O}$ techniques experience oscillations around the maximum power point (MPP) due to fluctuations in the operating point when the PV system approaches the MPPT [3]. Furthermore, this becomes a steady-state error which ultimately causes a loss of energy produced or should be extracted. In addition, $\mathrm{P} \& \mathrm{O}$ is also unable to track MPP in rapidly changing environmental conditions due to slow convergence. Then, in applying the $\mathrm{P} \& \mathrm{O}$ algorithm, it is difficult to determine the number of steps for each updating step.

Faced with this, the researchers developed MPPT techniques based purely on non-linear or artificial intelligence such as Artificial Neural Network (ANN) [4], fuzzy logic [5], and metaheuristics such as Ant Colony Optimization, Particle Swarm Optimization (PSO), and Cuckoo Search Algorithm [6]. These non-linear and artificial intelligence-based MPPT techniques also have drawbacks, including The ANN-based MPPT technique requires a large amount of data (different irradiation,

\footnotetext{
* Corresponding author: imran@eng.unand.ac.id
} 
temperature, and partial shading conditions) for proper training, [7]. Metaheuristic-based methods show extreme transient behavior during the search for optimal parameters (duty cycle or reference voltage). This causes convergence to be achieved more slowly and may result in early convergence under rapidly changing environmental conditions [8]. Meanwhile, Fuzzy Logic Control (FLC) offers moderate computational complexity and has an efficiency comparable to ANN. However, FLC design requires designers to have complete knowledge of $\mathrm{PV}$ operations and FLC rule tables can lead to computational improvements, if not optimized properly [9]. To overcome this weakness, various combinations of intelligent techniques are proposed, for example, the Particle Swarm Optimization (PSO) technique [10], is used to optimize the membership function and FLC rules. Then in the literature [11], FLC combined with Hopfield ANN is used to calculate and determine fuzzy rules (fuzzy rules table). The intelligence-based MPPT technique combined with these other techniques provides an advantage in dealing with inaccuracies and parameter variations [12].

In this paper, fuzzy logic as the non-linear controller is integrated into the conventional MPPT P\&O algorithm, by exploiting the advantages of the MPPT P\&O technique, while the shortcomings of artificial intelligence Fuzzy techniques that require expertise in planning are relatively accommodated, considering that knowledge of PV module behaviour as a condition for fuzzy implementation is sufficiently mastered by designer. The MPPT P\&O technique in operation controls the PV array output power through a PWM switching mechanism in a photovoltaic generation system (Fig. 1). The P\&O MPPT control algorithm is based on the calculation of the PV output power and the power change. These signals are acquired by sampling the voltage and current of the module or array. The power and voltage change is detected by comparing their present and previous levels and used to change the reference voltage by adding or subtracting a voltage change $(\Delta V)$. Furthermore, fuzzy logic is used to vary the magnitude of this $\Delta \mathrm{V}$ according to its position concerning the MPP point. With this combination, the problem of oscillation around the MPP which is the main weakness of the MPPT P\&O method can be reduced.

In applying this Fuzzy and $\mathrm{P} \& \mathrm{O}$ combination method, the next problem faced is to increase the MPPT response performance so that conversion efficiency can be optimized. The addition of fuzzy logic to the MPPT algorithm however provides additional processes that must be passed to produce the final output of the controller signal. This must be compensated by a response acceleration strategy that can be applied to the membership function design or fuzzy logic membership used. For this reason, a strategy to improve MPPT performance is proposed by adjusting the level of $\Delta \mathrm{V}$ in tracking the optimum working point of the PV module. It takes into account the wide range of $\mathrm{dP} / \mathrm{dV}$ oscillation values in the area to the left and right of the maximum operating point on the PV characteristic curve. The range of each membership function is different between the two so that the membership curve profile is not symmetrical.

\section{PV Module Characteristic and Fuzzy P\&O MPP Tracker}

A simple diagram of an ESS is shown in Fig. 1. It consists of main components such as primary energy sources, in this case, a module or array of photovoltaic arrays, energy storage components in the form of a battery bank, DC-DC converter for charging/discharging, and DC-AC converter as the interface between this energy storage system and the load. A transformer is also sometimes needed to adjust the system voltage level. In this system, the MPPT mechanism in the form of a control algorithm is placed on the DC-DC charging/discharging converter.



Fig. 1. An energy storage system with photovoltaic as a primary energy source.

PV module or array as Fig. 1 can be modeled according to [13], from [14] and [15],

$$
\mathrm{I}=\mathrm{I}_{\mathrm{LG}}-\mathrm{I}_{\mathrm{os}}\left\{\exp \left[\frac{\mathrm{q}}{\mathrm{AkT}}\left(\mathrm{V}-\mathrm{IR}_{\mathrm{s}}\right)\right]-1\right\}-\frac{\mathrm{V}-\mathrm{IR}_{\mathrm{s}}}{\mathrm{R}_{\mathrm{sh}}}
$$

Where

$$
\begin{aligned}
& \mathrm{I}_{\mathrm{OS}}=\mathrm{I}_{\mathrm{Or}}\left[\frac{\mathrm{T}}{\mathrm{T}_{\mathrm{r}}}\right]^{3} \exp \left[\frac{\mathrm{qE}_{\mathrm{GO}}}{\mathrm{B}_{\mathrm{k}}}\left(\frac{1}{\mathrm{~T}_{\mathrm{r}}}-\frac{1}{\mathrm{~T}}\right)\right] \\
& \mathrm{I}_{\mathrm{LG}}=\left[\mathrm{I}_{\mathrm{SCR}}+\mathrm{K}_{\mathrm{I}}(T-25)\right] \frac{\lambda}{100}
\end{aligned}
$$

and

I and V cell output current and voltage;

$\mathrm{I}_{\mathrm{os}} \quad$ cell reverse saturation current;

$\mathrm{T} \quad$ cell temperature in $\mathrm{C}$;

k Boltzmann's constant;

q electronic charge;

$\mathrm{K}_{\mathrm{I}} \quad$ short circuit current temperature coefficient at ISCR;

$\lambda$ solar irradiation in $\mathrm{W} / \mathrm{m}$

$\mathrm{I}_{\mathrm{SCR}} \quad$ short-circuit current at $25 \mathrm{C}$ and $1000 \mathrm{~W} / \mathrm{m}$;

$\mathrm{I}_{\mathrm{LG}} \quad$ light-generated current;

$\mathrm{E}_{\mathrm{GO}} \quad$ band gap for silicon;

$\mathrm{B}=\mathrm{A} \quad$ ideality factors, 1.92 ;

$\mathrm{T}_{\mathrm{r}} \quad$ reference temperature;

$\mathrm{I}_{\text {or }} \quad$ cell saturation current at ;

$\mathrm{R}_{\mathrm{sh}} \quad$ shunt resistance;

$\mathrm{R}_{\mathrm{se}} \quad$ series resistance. 
By multiplying both sides of equation (1) by Voltage $\mathrm{V}$, we get the power equation of the PV module $\mathrm{P}(\mathrm{V})$. The plot of the power as a function of module voltage, at a given temperature and irradiance condition, is shown in Fig. 2., where MPP points are seen at the top of the curve. The figure also shows the $\mathrm{dP} / \mathrm{dV}$ parameter, which is the rate of change of the extracted power to the voltage of the module. These three-parameter positions are shown on the $\mathrm{P}(\mathrm{V})$ curve, namely the position on the curve where the slope (gradient) $\mathrm{dP} / \mathrm{dV}>0$ is to the left of the MPP and the slope (gradient) $\mathrm{dP} / \mathrm{dV}<0$ is to the right of the MPP.

The traditional $\mathrm{P} \& \mathrm{O}$ algorithm is depicted with a flowchart as shown in Fig. 3. The MPP point can be tracked. This algorithm continuously calculates the value of module power from voltage and current signal that is sensed at the PV module output. If there is a change in power, then the $\mathrm{P} \& \mathrm{O}$ algorithm will take action to increase or decrease the reference voltage Vref on the DCDC converter operating control system. Furthermore, in the converter control system, this reference voltage change is used to adjust the duty ratio of the PWM signal as the gating of the converter's switching components.

The change in the converter reference voltage Vref is done by adding or subtracting a voltage change $\Delta \mathrm{V}$ to the converter's operating reference voltage in the previous sample. The value of $\Delta \mathrm{V}$ is predetermined by the designer. $\mathrm{P} \& \mathrm{O}$ algorithm will change the converter output voltage reference along with the condition of the $\mathrm{dP} / \mathrm{dV}$ gradient position [3]. If the gradient is $\mathrm{dP} / \mathrm{dV}>0$ then $\Delta \mathrm{V}$ will be subtracted from the previous reference, and if the gradient is $\mathrm{dP} / \mathrm{dV}<0$ then $\Delta \mathrm{V}$ will be added until $\mathrm{dP} / \mathrm{dV}=0$, i.e. when the operating point of the module is at its optimum.

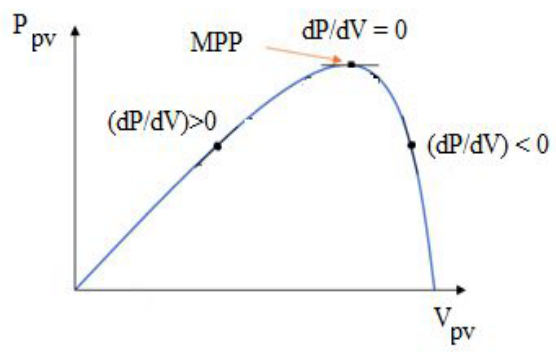

Fig. 2. $P(V)$ characteristic curve of a photovoltaic module.

In the development of the $\mathrm{P} \& \mathrm{O}$ algorithm into Fuzzy$\mathrm{P} \& \mathrm{O}$, fuzzy logic is used to adjust the $\Delta \mathrm{V}$ voltage which was fixed in the traditional P\&O. Fuzzy logic makes the gradient or rate of change of the extracted power to the voltage, $\mathrm{dP} / \mathrm{dV}$, as the input error signal $\mathrm{E}(\mathrm{n})$, and changes in the $\mathrm{dP} / \mathrm{dV}$ as input signal delta-error, $\mathrm{dE}(\mathrm{n})$. error signal $(\mathrm{E}(\mathrm{n}))$ serves to determine the location of the photovoltaic power gradient while delta-error $(\mathrm{dE}(\mathrm{n}))$ serves to determine the level of error change.

The value of $\Delta \mathrm{V}$ is varied, which is determined based on the previously compiled Fuzzy rule. This can be seen in the flowchart in Fig. 4

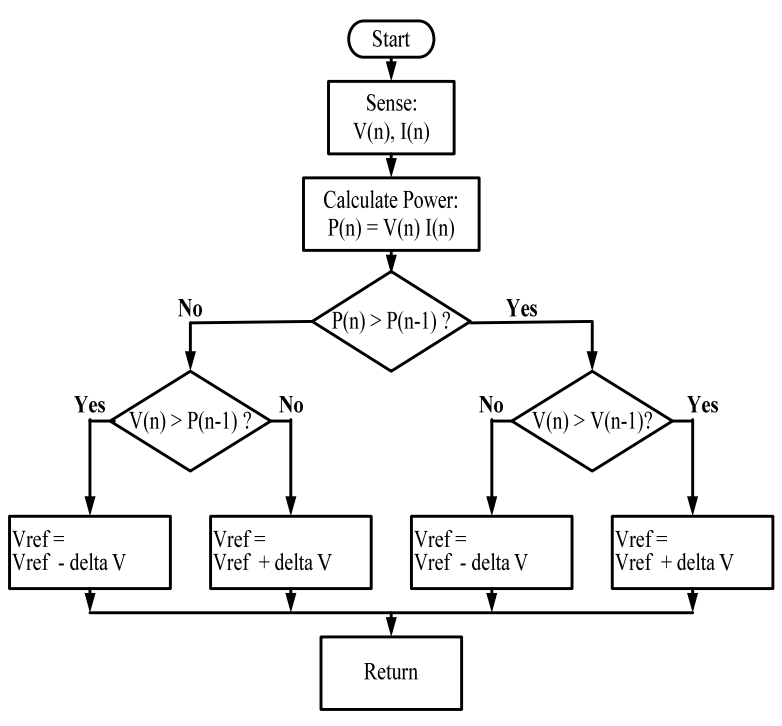

Fig. 3. Flowchart of $\mathrm{P} \& \mathrm{O}$ algorithm to track the position of MPP on the $\mathrm{P}(\mathrm{V})$ characteristic curve of PV module.

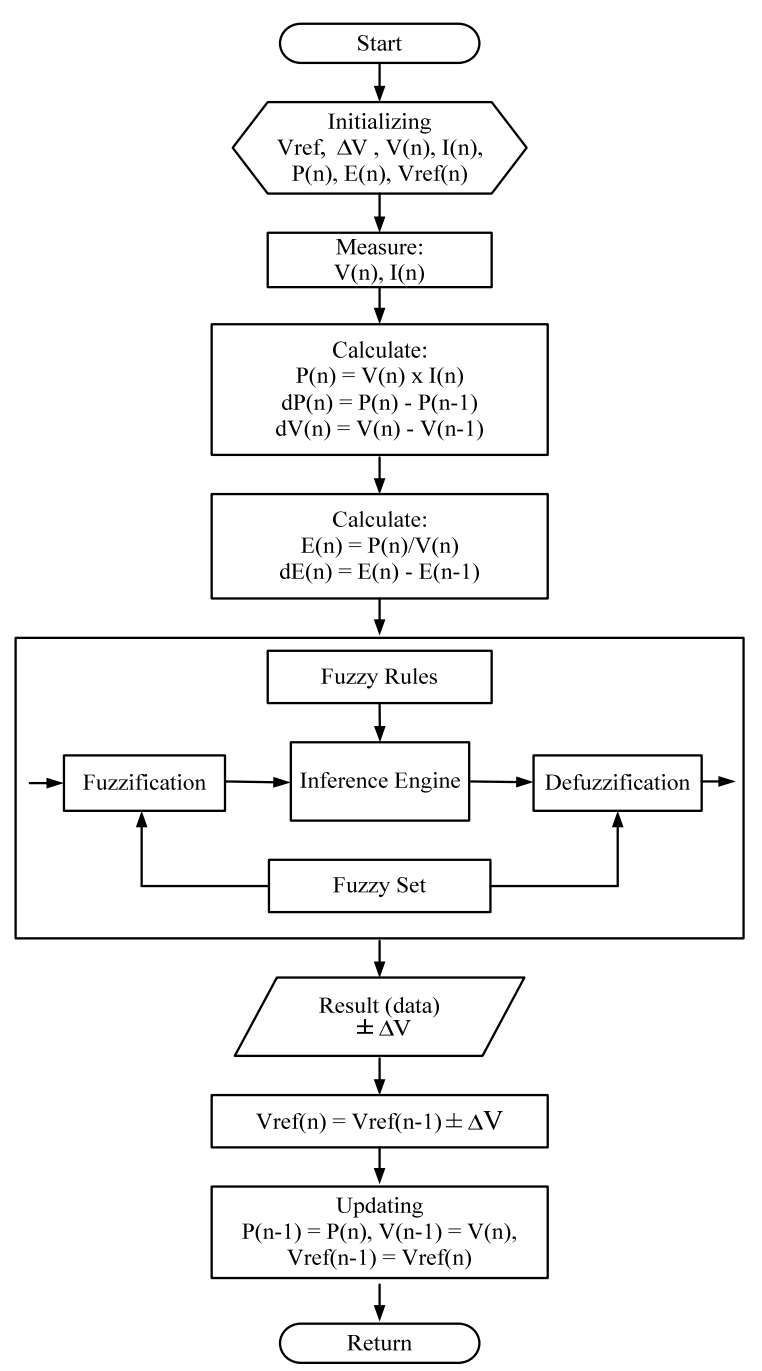

Fig. 4. Flowchart of Fuzzy-P\&O algorithm to track the position of MPP on the $\mathrm{P}(\mathrm{V})$ characteristic curve of $\mathrm{PV}$ module. 


\section{Proposed Fuzzy Set Design for Fuzzy-P\&O MPPT Algorithm}

In this section, we will discuss the methods in membership function design, testing, and simulation. Based on Fig. 4., it can be seen that the focus of fuzzy controller design is aimed at the following three aspects: the preparation of fuzzy sets in the process of fuzzyfication and defuzzification, and the determination of the rule-based fuzzy.

The fuzzy set in the fuzzyfication step is formed based on the photovoltaic power slope characteristic data obtained from the PV module test to obtain the $\mathrm{P}(\mathrm{V})$ characteristic curve. Furthermore, for each segment on this curve, the value of $\mathrm{dP} / \mathrm{dV}$ and its changes can be obtained which are used as input error signals $E(n)$ and delta error dE(n) for fuzzy blocks. As a test case data from a PV module with data as Table 1.

From the simulation, the range of $\mathrm{dP} / \mathrm{dV}$ is between (206.72) on the right side of MPP to (15.2) on the left side. The PV power characteristic curve has an asymmetrical parabolic shape. The right and left sides of the MPP have different power gradients, the steeper the curve, the greater the power gradient. This condition causes the power gradient range of the right side to be larger than the left side of the MPP and of course, the power gradient to the right side of the MPP is also negative because the direction of the curve is linearly decreasing. With this range, six fuzzy sets for $\mathrm{E}(\mathrm{n})$ are formed. Also, five fuzzy sets for delta error $\mathrm{dE}(\mathrm{n})$ and $\Delta \mathrm{V}$. The boundaries for each fuzzy set are determined as follows:

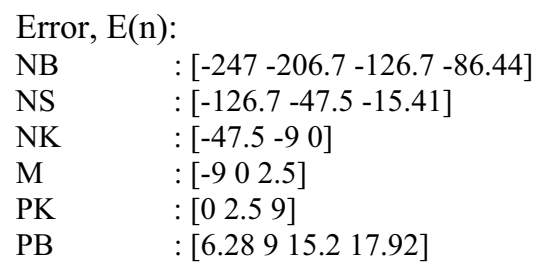

delta error, $\operatorname{dE}(\mathrm{n})$ :

$\begin{array}{ll}\text { NB } & :\left[\begin{array}{llll}-0.024 & -0.02 & -0.008 & -0.004\end{array}\right] \\ \text { NK } & :\left[\begin{array}{lll}-0.008 & -0.004 & 0\end{array}\right] \\ \text { M } & :\left[\begin{array}{lll}-0.0015 & 0 & 0.0015\end{array}\right] \\ \text { PK } & :\left[\begin{array}{llll}0 & 0.004 & 0.008\end{array}\right] \\ \text { PB } & :\left[\begin{array}{llll}0.004 & 0.008 & 0.02 & 0.024\end{array}\right]\end{array}$

Voltage reference change, $\Delta \mathrm{V}(\mathrm{n})$ :

$\begin{array}{ll}\text { NB } & :\left[\begin{array}{llll}-1.3 & -1 & -0.6 & -0.3\end{array}\right] \\ \mathrm{NK} & :\left[\begin{array}{lll}-0.6 & -0.3 & 0\end{array}\right] \\ \mathrm{M} & :\left[\begin{array}{lll}-0.1 & 0 & 0.1\end{array}\right] \\ \mathrm{PK} & :\left[\begin{array}{llll}0 & 0.3 & 0.6\end{array}\right] \\ \mathrm{PB} & :\left[\begin{array}{llll}0.3 & 0.6 & 1 & 1.3\end{array}\right]\end{array}$

The rule base table that connects the resulting input and output fuzzy $\Delta \mathrm{V}$ is shown in Fig 5. The base rules in the table use if-then rules. Defuzzyfication to produce a crisp value of $\mathrm{V}$ is carried out through the fuzzy inference system using the Mamdani method. The range that will be used to change the $\Delta \mathrm{V}$ level is \pm 1.3 Volts.
Table 1. Parameter of the PV Array at $\mathrm{G}=1000 \mathrm{~W} / \mathrm{m}^{2}$.

\begin{tabular}{|c|c|}
\hline Parameters & Value \\
\hline Maximum Power $\left(\mathrm{P}_{\max }\right)$ & 6224 Watt \\
\hline Voltage Maximum Power $\left(\mathrm{V}_{\mathrm{mp}}\right)$ & 444.6 Volt \\
\hline Current Maximum Power $\left(\mathrm{I}_{\mathrm{mp}}\right)$ & $14 \mathrm{~A}$ \\
\hline Short Circuit Current $\left(\mathrm{I}_{\mathrm{sc}}\right)$ & $15.2 \mathrm{~A}$ \\
\hline Open Circuit Voltage $\left(\mathrm{V}_{\mathrm{oc}}\right)$ & 527.5 Volt \\
\hline
\end{tabular}

Table 2. Fuzzy rule base table.

\begin{tabular}{|c|c|c|c|c|c|c|}
\hline E & NB & NS & NK & M & PK & PB \\
\hline NB & PB & PB & PB & PK & M & NK \\
\hline NK & PB & PB & PK & M & NK & NK \\
\hline M & PB & PK & PK & M & NK & NB \\
\hline PK & PB & PK & PK & M & NK & NB \\
\hline PB & PB & PK & M & NK & NB & NB \\
\hline
\end{tabular}

\section{Results}

To evaluate the performance of the Fuzzy-P\&O MPPT development, testing was carried out using the Simulink software. A simulation circuit to execute MPPT algorithm on a DC to DC converter type interleaved DC-DC converter is built. Furthermore, this circuit is operated by input power from the photovoltaic module where the amount of power towards the converter circuit and the MPPT algorithm can be adjusted by varying the level of irradiance received by the PV module. Furthermore, the extraction efficiency and power response on the converter side are acquired and analyzed. Three simulation conditions were carried out, namely the operation of the DC-DC converter system in distributing power from the PV module without applying the MPPT algorithm; implementation of conventional P\&O MPPT, and application of Fuzzy-P\&O MPPT. Fig. 5. shows the full system converter simulation diagram on the Matlab/Simulink software (upper); PV module model diagram (middle), and Fuzzy P\&O implementation diagram (lower).

Based on the power generated in the simulation, it can be seen that the Fuzzy Perturb and Observe can track the MPP of the PV array faster: $14 \mathrm{~ms}$, than the conventional Perturb and Observe which takes $156 \mathrm{~ms}$, this shows that Fuzzy technology can improve the quality of MPPT P\&O in tracking the photovoltaic MPP. In addition, the power of the PV Array that can be generated by Fuzzy Perturb and Observe is also greater, when the Irradiance $1000 \mathrm{~W} / \mathrm{m}^{2}$ Fuzzy P\&O produces $6207.83 \mathrm{~W}$ of power while the PO is only able to generate $6078.91 \mathrm{~W}$ of power. Table 2 shows the output power value generated for each irradiance level 


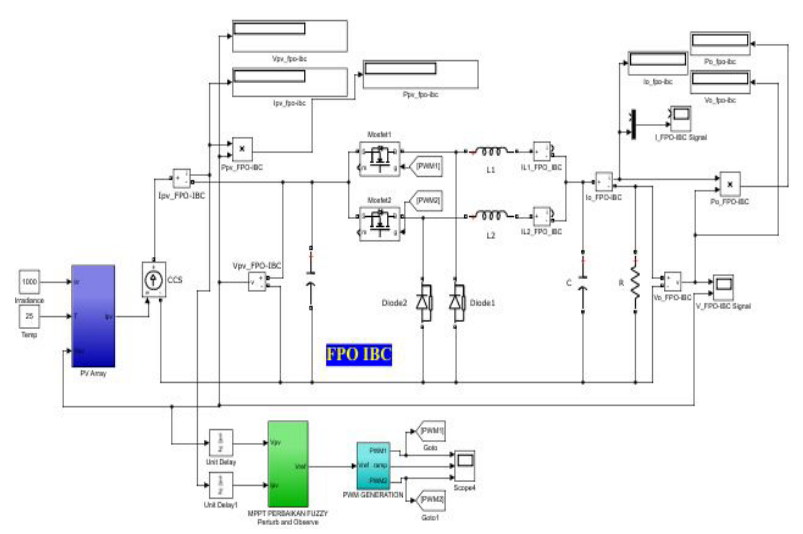

Table 2. System output power for various operation schemes
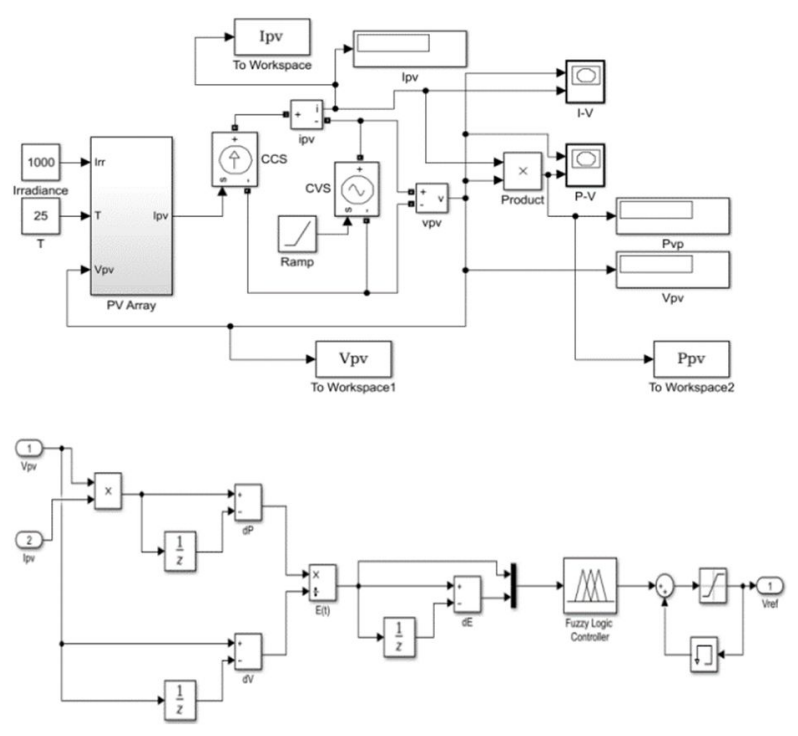

Fig. 5. Simulation diagram of Fuzzy-P\&O MPPT on Interleaved DC-DC converter


Fig. 6. PV system output power at Irradiance $1000 \mathrm{~W} / \mathrm{m}^{2}$, (a) Response of the MPPT to the irradiance, and (b) detail response.

$$
\eta=\frac{P_{M P P T-x}}{P_{M a x}} \times 100 \%
$$

Where

$\eta \quad$ efficiency of power extraction

$\mathrm{P}_{\text {MPPT-X }}$ output power using the $\mathrm{x}$-type MPPT

$\mathrm{P}_{\mathrm{Max}} \quad$ output power from $\mathrm{PV}$ array

The resulting power extraction efficiency conditions as outlined in Table 3.

Table 3. Power extraction efficiency

\begin{tabular}{|c|c|c|c|}
\hline \multirow{2}{*}{$\begin{array}{c}\text { Irradiance } \\
\left(\mathbf{W} / \mathbf{m}^{2}\right)\end{array}$} & \multicolumn{3}{|c|}{ PV System output } \\
\cline { 2 - 4 } & $\begin{array}{c}\text { Without } \\
\text { MPPT }\end{array}$ & FPO-IBC & PO-IBC \\
\hline 400 & $497.91 \mathrm{~W}$ & $1128.33 \mathrm{~W}$ & $1048.18 \mathrm{~W}$ \\
\hline 600 & $1119.16 \mathrm{~W}$ & $2525.25 \mathrm{~W}$ & $2347.77 \mathrm{~W}$ \\
\hline 800 & $1988.52 \mathrm{~W}$ & $4396.14 \mathrm{~W}$ & $4126.68 \mathrm{~W}$ \\
\hline 1000 & $3105.74 \mathrm{~W}$ & $6207.83 \mathrm{~W}$ & $6078.91 \mathrm{~W}$ \\
\hline
\end{tabular}

From the simulation carried out by applying the same Fattern and level: $1000 \mathrm{~W} / \mathrm{m} 2$, an analysis of the power extraction efficiency was carried out, using the equation:

\begin{tabular}{|c|c|c|}
\multicolumn{3}{|c|}{ MPPT Implementation } \\
\hline None & P\&O & Fuzzy P\&O \\
\hline 89 & 99.74 & 97.66 \\
\hline
\end{tabular}

MPPT Perturb and Observe have high power efficiency in optimizing photovoltaic power compared to MPPT with other algorithms, with the application of Fuzzy technology in Perturb and Observe, MPPT P\&O on photovoltaic systems has a faster response in tracking with a large power efficiency of $99.74 \%$.

\section{Conclusion}

The performance of the traditional MPPT development of P\&O type by utilizing a non-linear Fuzzy algorithm into a Fuzzy-P\&O algorithm has been described. In this paper, a fuzzy set method has also been introduced which is based on the condition of the $\mathrm{dP} / \mathrm{dV}$ value of the powerto-voltage characteristic curve of the photovoltaic module. The fuzzy set is arranged in an asymmetrical shape that resembles the power function characteristic curve of the PV module voltage. The speed of response and also the increase in the efficiency of the resulting power extraction are the advantages of this algorithm. With these results, it can be said that the development of MPPT that combines traditional methods and non-linear techniques such as fuzzy perspective is to be developed.

The authors would like to express gratitude to Universitas Andalas for providing financial support under Fundamental Research Grant (RD), Contract No. T/9/UN.16.17/PT.01.03/Energi-RD/2021. 


\section{References}

1. M. I. Hamid, M Anwari, Single-Phase PhotovoltaicInverter Operation Characteristic in Distributed Generation System, Distributed Generation, D N Gaonkar, IntechOpen,(2010)

2. A. R. Jordehi., Maximum power point tracking in photovoltaic (PV) systems: A review of different approaches. Renewable and Sustainable Energy Reviews; 65:1127-1138 (2016)

3. S. K. Kollimalla, M. K. Mishra, A novel adaptive P\&O MPPT algorithm considering sudden changes in the irradiance. IEEE Transactions on Energy conversion; 29 (3), 602-610 (2014)

4. S. Saravanan, N. R. Babu, RBFN based MPPT algorithm for PV system with high step up converter. Energy Conversion and Management; 122:239-251 (2016)

5. N. Karami, N. Moubayed, R. Outbib General review and classification of different MPPT Techniques. Renewable and Sustainable Energy Reviews; 68:118 (2017)

6. J. P. Ram, T. S. Babu, N. A Rajasekar comprehensive review on solar PV maximum power point tracking techniques. Renewable and Sustainable Energy Reviews; 67:826-847 (2017)

7. Z. Salam, J. Ahmed J, B. S. Merugu, The application of soft computing methods for MPPT of PV system: A technological and status review. Applied Energy; 107:135-148 (2013)

8. A. Khare, S. Rangnekar, A review of particle swarm optimization and its applications in the solar photovoltaic system. Applied Soft Computing; 13 (5):2997-3006 (2013)

9. N. Karami, N. Moubayed, R. Outbib, General review and classification of different MPPT Techniques. Renewable and Sustainable Energy Reviews; 68:1-18 (2017)

10. Y. Soufi, M. Bechouat, S. Kahla. Fuzzy-PSO controller design for maximum power point tracking in the photovoltaic system. International Journal of Hydrogen Energy; 42(13):8680-8688 (2017)

11. R. Arulmurugan, N. Suthanthiravanitha. Model and design of a fuzzy-based Hopfield NN tracking controller for standalone PV applications. Electric Power Systems Research; 120:184-193 (2015)

12. L. Suganthi, S. Iniyan, A. A. Samuel, Applications of fuzzy logic in renewable energy systems-a review. Renewable and Sustainable Energy Reviews; 48: 585-607 (2015)

13. E. Koutroulis, K. Kalaitzakis, "Development of a Microcontroller-Based Photovoltaic Maximum Power Point Tracking Control System, IEEE Trans. On Power Electronics., 16 (1) (2001)

14. G. Vachtsevanos and K. Kalaitzakis, "A hybrid photovoltaic simulator for utility-interactive studies," IEEE Trans. Energy Conv., EC-2, 227231, (1987)

15. M. G. Jaboori, M. M. Saied, and A. A. Hanafy, "A contribution to the simulation and design optimization of photovoltaic systems," IEEE Trans. Energy Conv., 6, 401-406 (1991) 